Research Paper

\title{
Functional Role of FcyRIIB in the Regulation of Mesenchymal Stem Cell Function
}

\author{
Tianyi Zhu ${ }^{1}{ }^{2}$, Ruohua Chen ${ }^{*}$, Zeng $\mathrm{Li}^{4^{*}}$, Jun Tian ${ }^{5}$, Changwen Deng1, Xingxing Zhang1, Koudong \\ Zhang $^{6}$, Linrong Tong 7 , Yizhi Yu ${ }^{8 凶}$, Chong Bai ${ }^{\circledR}$ \\ 1. Department of Respiratory, Changhai Hospital, Second Military Medical University, Shanghai 200433, China; \\ 2. Department of Respiratory, The General Hospital of Shenyang Military, Shenyang, Liaoning, 110015, China; \\ 3. Department of VIP Treatment, Changhai Hospital, Second Military Medical University, Shanghai 200433, China; \\ 4. Department of Orthopedics, The First Affiliated Hospital of Nanjing Medical University, Nanjing, Jiangsu, 210000, China; \\ Department of Immunology, Zhejiang University, Hangzhou, Zhejiang310000, China; \\ 6. Department of Respiratory, No. 1 People's Hospital of Yancheng, Yancheng, Jiangsu, 224000, China: \\ 7. Department of Respiratory, The 174 Hospital, Xiamen, Fujian, 361000, China \\ 8. Institute of Immunology, The Second Military Medical University, Shanghai, 200433, China \\ * These authors contributed equally to this study.
}

$\triangle$ Corresponding authors: Prof. Chong Bai, Department of Respiratory, Changhai Hospital, Second Military Medical University, Shanghai 200433, China. Telephone: +86-21-31161312, Fax: +86-21-31161312. E-mail: bc7878@sohu.com Or Prof. Yizhi Yu, Institute of Immunology, The Second Military Medical University, Shanghai 200433, China. Tel/Fax: +86021-81871101. Email: yuyz88@126.com.

(C) Ivyspring International Publisher. Reproduction is permitted for personal, noncommercial use, provided that the article is in whole, unmodified, and properly cited. See http://ivyspring.com/terms for terms and conditions.

Received: 2015.08.24; Accepted: 2015.11.27; Published: 2016.02.05

\begin{abstract}
Mesenchymal stem cells (MSCs) derived from bone marrow are plural-potent stem cells with immune regulatory functions. We aimed to evaluate role of FcyRIIB in the regulation of bone marrow-derived MSC function. MSCs were prepared from mouse bone marrow derived from wild-type (WT) or FcyRIIB-deficient (FcyRIIB-/-) mice. MSCs were co-cultured with bone marrow-derived dendritic cells (BMDCs), and BMDC maturation and function were evaluated by flow cytometric analysis and carboxyfluorescein succinimidyl ester-labeled OT-II T-cell addition. An acute asthma model was established by aeresol ovalbumin challenge in mice. Mice received WT or FcyRIIB-/- MSC therapy. Lung function was evaluated by histological examination and cytokine production measurement. mRNA and protein expression levels of target genes were examined by real-time quantitative polymerase chain reactionor western blotting. We found that MSCs derived from bone marrow exhibit a high level of FcyRIIB expression. FcyRIIB deficiency impaired the suppressive function of MSCs, as FcyRIIB deficiency efficiently reversed the inhibitory effect of MSCs on BMDC maturation and function. Additionally, FcyRIIB-/-MSCs were less potent at suppressing asthma in model mice, possibly through reduced expression of Smad2, Smad3, Cox-2, and prostaglandin E2 in FcyRIIB-/-MSCs. FcyRIIB might play an essential role in regulating the inhibitory effects of MSCs derived from bone marrow.
\end{abstract}

Key words: mesenchymal stem cells; FcүRIIB; dendritic cell maturation; asthma.

\section{Introduction}

Mesenchymal stem cells (MSCs), multi-potential stem cells that reside largely within the bone marrow, have the capacity to differentiate into many cell lineages, such as adipocytes, osteocytes, and chondrocytes [1]. The MSCs derived from bone marrow exert immunomodulatory effects and have been widely studied in various human immune disorders, especially in autoimmune diseases [2-4]. Accumulating evidence suggests that MSCs derived from bone marrow have the ability to suppress allergic responses in asthma [5-7]. However, the underlying mechanism remains unclear.

$\mathrm{Fcy}$ receptor II ( $\mathrm{Fc} \gamma \mathrm{RII}$, also known as CD32) is a surface receptor mainly expressed on leukocytes, including B cells, follicular dendritic cells, macrophages, and neutrophils [8]. FcyRIIB is a low-affinity inhibi- 
tory $\mathrm{F}_{\mathrm{C}}$ receptor that is highly homologous on its extracellular domain to the activating $\mathrm{Fcy}$ receptor FcyRIIA [9]. Although FcyRIIB is known for its inhibitory effects on cell activation and cytokine production in many cell types, such as natural killer cells [10] and phagocytes [11], the potential role of $F_{c \gamma}$ RIIB in the regulation of MSC function is still poorly understood.

In the present study, we investigated the influence of FcyRIIB on the biological functions of MSCs. To address this point, FcyRIIB-deficient (FcyRIIB-/-) mice were used, and the functions of MSCs derived from wild-type (WT) or FcyRIIB-/- mice were compared in vitro. Furthermore, a mouse acute asthma model was developed, and the differences in the in vivo function of MSCs derived from WT or FcyRIIB-/mice were studied. Our findings may provide valuable insights into understanding the biological significance of FcyRIIB in mediating MSC function.

\section{Materials \& Methods}

\section{Animals}

Balb/c and C57/B6 mice were purchased from BK Experimental Animal (Shanghai, China). FcyRIIB knockout (FcyRIIB-/-) mice were purchased from Jackson lab (Bar Harbor, ME, USA). All mice were housed in specific pathogen-free conditions. All experimental procedures were conducted in accordance with the National Institutes of Health Guide for the Care and Use of Laboratory Animals. The animal experiments were performed with the approval of the Scientific Investigation Board of Second Military Medical University (Shanghai, China).

\section{Reagents}

Chicken ovalbumin (OVA) was obtained from Sigma-Aldrich (St. Louis, MO, USA). Mouse fluorescein-conjugated antibodies against CD11c, I-A ${ }^{\mathrm{b}}, \mathrm{CD} 80$, CD86, CD40, and FcyRIIB were purchased from eBioscience. Enzyme-linked immunosorbent assay (ELISA) kits for the detection of mouse interleukin (IL)-12, IL-6, IL-4, and IL-13 as well as an enzyme immunoassay (EIA) kit for evaluation of prostaglandin E2 (PGE2) were bought from R\&D Systems (Minneapolis, MN, USA).Rabbit anti-mouse Cox-2 and horseradish peroxidase (HRP)-conjugated anti-rabbit Ig secondary antibodies were purchased from Abcam (Cambridge, UK).

\section{MSC culture and characterization}

MSCs were prepared from mouse bone marrow (BM) derived from (WT) or FcyRIIB-/- C57/B6 mice as described previously [12]. Briefly, BM cells were flushed from femurs of mice and the red blood cells were lysed by incubating cells in Tris- $\mathrm{NH}_{4} \mathrm{Cl}$ solution for 2 min. BM cells were maintained in Dulbecco's Modified Eagle Medium containing 10\% fetal bovine serum (FBS), $100 \mathrm{U} / \mathrm{ml}$ penicillin, $100 \mu \mathrm{g} / \mathrm{ml}$ streptomycin, and $6 \mathrm{ng} / \mathrm{ml}$ basic fibroblast growth factor (bFGF) for 7 days for in vitro differentiation. Cells were incubated in a $5 \% \mathrm{CO}_{2}$-humidified incubator at $37^{\circ} \mathrm{C}$. The adherent cells were detached using trypsin-ethylene diamine tetraacetic acid (EDTA) and harvested for a new passage. After three passages, cells were harvested and used for flow cytometric analysis. Adherent cells after three passages were able to differentiate into adipocytes and chondrocytes in vitro.

\section{Bone marrow-derived dendritic cell (BMDC) culture}

BMDCs were prepared from mouse $\mathrm{BM}$ as described previously [13] with a minor modification. Briefly, BM cells isolated and prepared from femurs of C57/B6 or FcyRIIB-/- mice were maintained in RMPI 1640 culture medium supplemented with $10 \% \mathrm{FBS}$, $10 \mathrm{ng} / \mathrm{ml}$ granulocyte-macrophage colony stimulating factor (GM-CSF), and 5ng/ml IL-4. On day 7 following initial seeding, non-adherent cells and loosely adherent cells were collected, stained with phycoerythin (PE)-conjugated anti-mouse CD11c microbeads and purified using fluorescence-activated cell sorting (FACS) applied in a flow cytometric system (LSR II, $\mathrm{BD})$.The purity of cultured BMDCs was greater than $80 \%$.

\section{Co-culture of MSCs with BMDCs}

Passage 4 or 5 MSCs were cultured in six-well plates at a density of $3 \times 10^{5}$ cells/well. After incubation in a $5 \% \mathrm{CO}_{2}$ incubator for 5-6 h, the culture medium was removed and replaced with $2 \mathrm{~mL}$ of BMDC suspension $\left(0.5 \times 10^{5}\right.$ cells $/ \mathrm{mL}$ in RPMI-1640 medium containing 5\% FBS). Cells were cultured in a $5 \%$ $\mathrm{CO}_{2}$-humidified incubator at $37^{\circ} \mathrm{C}$ until use in experiments.

\section{Determination of DC maturation and function}

BMDCs were stimulated with $100 \mathrm{ng} / \mathrm{ml}$ lipopolysaccharide (LPS) for $24 \mathrm{~h}$. The DC surface markers including $\mathrm{I}-\mathrm{A}^{\mathrm{b}}$ and $\mathrm{CD} 86$ were analyzed using flow cytometric analysis. Data were analyzed by FlowJo software. To evaluate BMDC function, OT-II T cells were purified by staining of OTII splenocytes with anti-mouse CD4 microbeads (Miltenyi Biotech). Purified OT-II T cells were labeled with carboxyfluorescein succinimidyl ester (CFSE) by incubating the cells with $5 \mu \mathrm{M}$ CFSE dissolved in phosphate-buffered (PBS) for $5 \mathrm{~min}$ at $37^{\circ} \mathrm{C}$. Then, BMDCs were incubated with CFSE-labeled OT-II $\mathrm{T}$ cells in the presence of $100 \mu \mathrm{M}$ OVA peptide for $72 \mathrm{~h}$ until flow cytometric analysis. 


\section{Mouse model of acute asthma}

Balb/c mice were actively sensitized by intra-peritoneal injection of $100 \mu \mathrm{g}$ OVA emulsified in aluminum hydroxide on days 1 and 14. Aerosol challenge was conducted from day 21 to day 24. Thirty minutes prior to challenge, mice were anesthetized with isofluorin and given $1 \times 10^{6}$ MSCs derived from either WT or FcyRIIB-/- mice intranasally. Intranasal administration of cell-free PBS was used as a control. During aerosol challenge, animals were treated once daily through a PARI Boy N (PARI GmbH, Germany) by holding $5 \mathrm{ml}$ 1\% OVA for $30 \mathrm{~min}$ from day 21 to day 24 . After the last challenge, mice were euthanized and blood samples were collected through cardiac puncture. Serum samples were collected for ELISA analysis using an OVA-specific IgE ELISA kit. Bronchoalveolar lavage fluid (BALF) was prepared using $1 \mathrm{ml}$ PBS. Total cell numbers in BALF, including lymphocytes, macrophages, eosinophils, and neutrophils, were counted after Gimsa staining. Supernatants of BALF were collected for ELISA analysis of cytokine production. Lung tissues were carefully removed, fixed in formalin, embedded in paraffin, and prepared as 5 - $\mu \mathrm{m}$-thick sections. Lung sections were subjected to hematoxylin and eosin (HE) staining for histological examination.

\section{Western blotting}

A total of $1 \times 10^{7}$ BMDCs derived from WT or FcyRIIB-/-mice were collected and lysed with $0.5 \mathrm{ml}$ lysis buffer containing $50 \mathrm{nM} \beta$ glycerophosphate, 0.1 $\mathrm{nM}$ orthovanadate sodium, $2 \mathrm{mM} \mathrm{MgCl} 2,1 \mathrm{mM}$ ethylene glycol tetraacetic acid (EGTA), $1 \mathrm{mM}$ DL-dithiothreitol (DTT), $1 \mathrm{mM}$ phenylmethanesulfonyl fluoride (PMSF), $10 \mu \mathrm{g} / \mathrm{ml}$ aprotinin, and $20 \mu \mathrm{M}$ leupeptin. Cell lysates were centrifuged at $12000 \mathrm{rpm}$

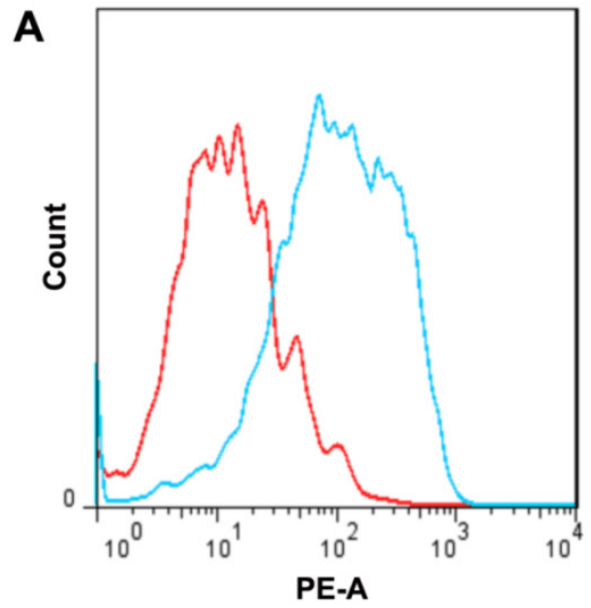

for $10 \mathrm{~min}$. A total of $30 \mu \mathrm{g}$ denatured proteins were separated on a $10 \%$ sodium dodecyl sulfate (SDS) polyacrylamide gel and transferred to a nitrocellulose (NC) membrane. Each membrane was blocked in 5\% non-fat dry milk in PBS containing $0.1 \%$ Tween 20at room temperature for $2 \mathrm{~h}$. Then, each membrane was probed with rabbit anti-mouse Cox-2 primary antibody and HRP-conjugated anti-rabbit Ig secondary antibody. Immunobands were visualized using an enhanced chemiluminescence (ECL) kit according to the manufacturer's instructions (Amersham Pharmacia Biotech).

\section{Statistical analysis}

Data were analyzed by SPSS17.0 software (IBM SPSS), Chicago, IL, USA) and were presented as means \pm standard deviation (SD). Statistical significance was determined using $t$ test. A difference with $P<0.05$ was recognized as significant.

\section{Results}

\section{Expression of FcyRIIB by MSCs}

To characterize the expression of FcyRIIB in MSCs, MSCs were isolated from bone marrow and cultured in vitro. Flow cytometric analysis using specific cell surface markers demonstrated that the cultured cells were CD29-, CD44-, and Flk-positive and CD45- and CD34-negative. In addition, these cells had the capability to differentiate into adipocytes or chondrocytes in vitro, indicating these cells had characteristics of MSCs derived from bone marrow. Flow cytometric analysis showed a significantly increased level of FcyRIIB in MSCs based on negative isotype staining (Fig. 1A). Moreover, very little FcyRIIB could be detected in MSCs derived from FcyRIIB-/- mice (Fig. 1B).

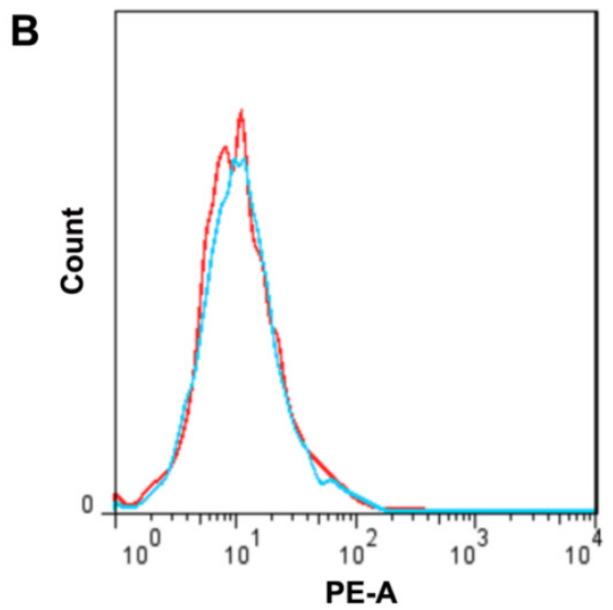

Figure 1. FcyRII expression in MSCs derived from WT and FcyRIIB-/- mice. The level of FcyRII in MSCs derived from either WT (A) or FcyRIIB-/- (B) mice was evaluated by flow cytometric analysis using phycoerthryin-conjugated anti-FcyRIIB antibody. Blue curve, FcyRII; red curve, isotype control. Representative data are presented. $\mathrm{n}=3$. 
A
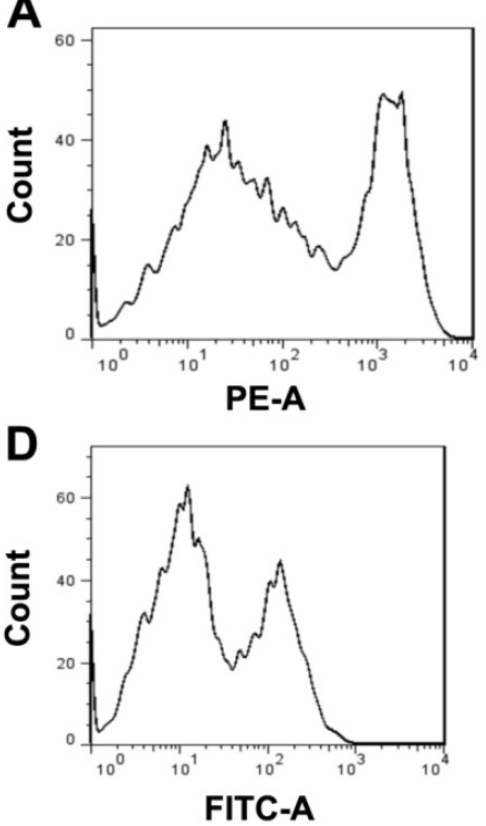

G

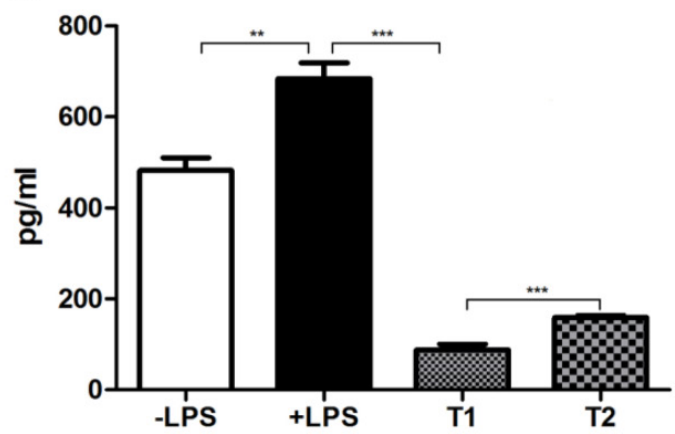

B

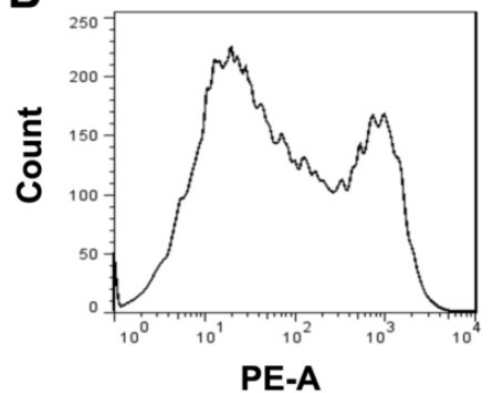

E

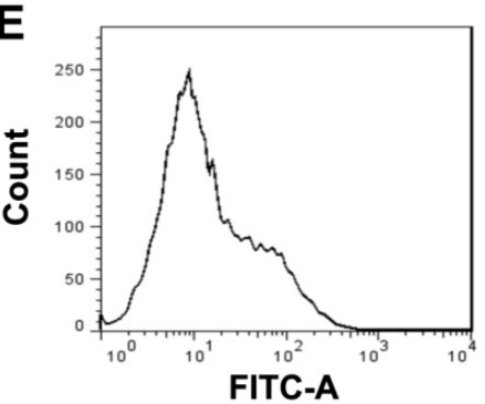

C

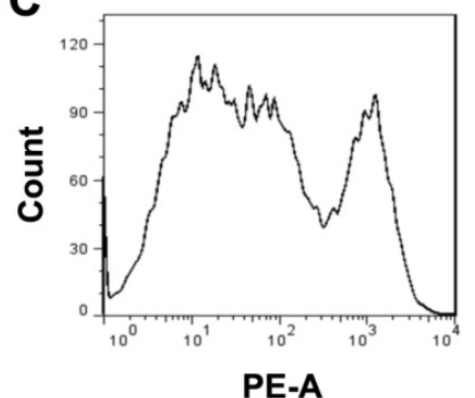

$\mathbf{F}$

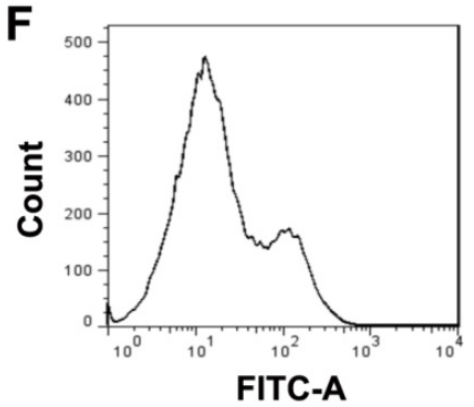

Figure 2. Effects of FcyRII on MSC-mediated DC maturation. BMDCs were cocultured without MSCs (A, D), with WT (B, E) or FcyRIIB-/- MSCs (C, F) in the presence of $100 \mathrm{ng} / \mathrm{ml}$ LPS. Cells were firstly gated on CDI lct population, and the expression of I-Ab (a-c) and CD86 (d-f) was analyzed. Data were acquired by flow cytometry and analyzed by Flowjo software. Representative data of three independent experiments are shown. (G) ELISA analysis of IL-12 level in BMDC culture supernatants. -LPS, BMDC culture supernatant without LPS stimulation; +LPS, BMDC culture supernatant with LPS stimulation; T1, LPS-stimulated BMDCs co-cultured with WT MSCs; T2, LPS-stimulated BMDCs co-cultured with FcyRIIB-/-MSCs. ** P<0.001; *** P<0.0001.

\section{Effects of FcyRIIB on MSC-mediated DC maturation}

We next investigated the influence of FcyRIIB deficiency on MSC function, such as the promotion of DC maturation. For this purpose, BMDCs were co-cultured with MSCs derived from WT mice. Upon LPS stimulation, the levels of the DC surface markers including $\mathrm{I}^{-\mathrm{A}^{\mathrm{b}}}$ and CD86 were greatly increased as compared with control (Fig. 2). However, co-culture of BMDCs with WT MSCs significantly suppressed the I- $\mathrm{A}^{\mathrm{b}}$ and $\mathrm{CD} 86$ expression. In addition, co-culture of BMDCs with MSCs derived from FcyRIIB-/- mice reversed the downregulation of $\mathrm{I}^{-\mathrm{A}^{\mathrm{b}}}$ and CD86 induced by WT MSC co-culture. Similarly, production of the proinflammatory cytokine IL-12 was also elevated in BMDCs after LPS stimulation as compared with control $(\mathrm{P}<0.001)$. The IL-12 secretion was remarkably decreased in BMDCs co-cultured with WT
MSCs $(\mathrm{P}<0.001)$, whereas co-culture of BMDCs with MSCs derived from FcyRIIB-/- mice reversed the reduction of IL-12 production induced by WT MSCs co-culture $(\mathrm{P}<0.001)$. These data indicate that MSCs play a suppressive role in DC maturation, and FcyRIIB deficiency efficiently reversed the inhibitory effect of MSCs on dendritic cell maturation.

\section{Effects of FcyRIIB in MSC-regulated anti- gen-specific $\mathrm{T}$-cell response}

To evaluate the effects of FcyRIIB on the MSC-regulated antigen-specific T-cell response, CFSC-labeled OT-II T cells were added to BMDCs co-cultured with MSCs derived from WT or FcyRIIB-/- mice in the presence of OVA. Seventy-two hours after incubation, the CFSE division was examined using flow cytometric analysis. As revealed by Fig. 3, the division capability of OT-II T cells in 
BMDCs co-cultured with FcyRIIB-/- MSCs was higher than that of cells co-cultured with WT MSCs, suggesting FcyRIIB-/- MSCs are less potent at suppressing the antigen-specific $\mathrm{T}$-cell response than WT MSCs.

\section{FcyRIIB-deficient MSCs are less potent at suppressing mouse experimental asthma}

We next tested the biological functions of FcyRIIB-/-MSCs in vivo using a mouse model of allergic asthma. Histological examination showed a normal lung structure in control animals (Fig. 4A). However, massive lymphocyte infiltration in lung tissues was observed in model mice after aerosol OVA challenge (Fig. 4B). Animals receiving WT MSC therapy exhibited significantly reduced leukocyte infiltration, especially eosinophil infiltration in lung (Fig. 4C), whereas FcyRIIB-/- MSC therapy only moderately inhibited leukocyte infiltration in lung (Fig. 4D). ELISA analysis demonstrated that serum OVA-specific IgE level was significantly elevated in asthma model mice $(\mathrm{P}<0.001)$, whereas WT MSC therapy greatly reduced the serum OVA level as compared with that in model mice $(\mathrm{P}<0.001$; Fig. 4E). Although FcyRIIB-/- MSC therapy also decreased the serum OVA level compared to that in model mice $(\mathrm{P}<0.05)$, its level was still higher than that in model mice that received WT MSCs $(\mathrm{P}<0.05)$. A similar trend was observed in the number of cells in BALF (Fig. 4F).

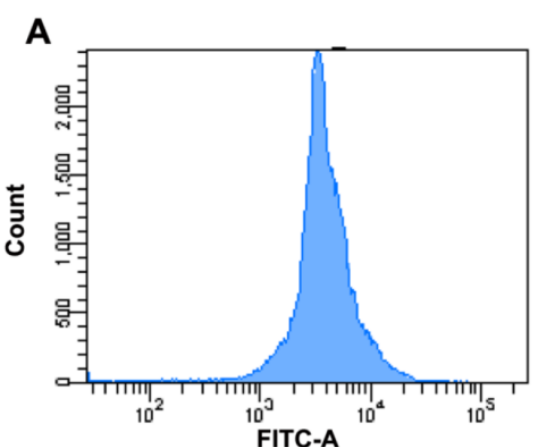

C

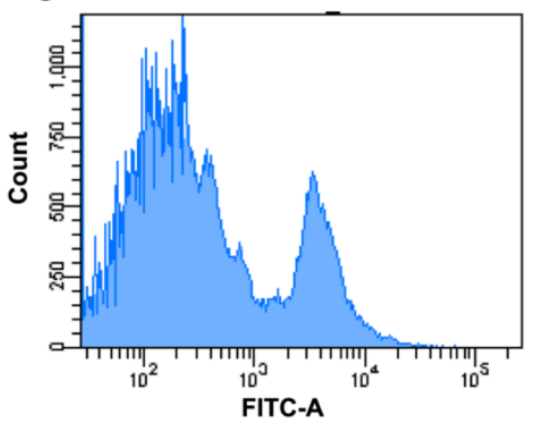

As IL-4 and IL-13 are two distinctive Th2 cytokines involved in the pathogenesis of asthma, we also assessed the production of IL-4 and IL-13 in BALF. As shown by Fig. $4 \mathrm{G}$ and $\mathrm{H}$, the levels of both IL-4 and IL-13 were elevated in asthma model mice $(\mathrm{P}<0.001)$. MSC therapy significantly reduced the IL-4 and IL-13 generation, and WT MSC therapy was more potent at decreasing their production as compared with Fc $\gamma$ RIIB-/- MSC therapy $(\mathrm{P}<0.05)$.

\section{Reduced production of Smad2, Smad3, Cox-2, and PGE2 in FcyRIIB-deficient MSCs}

To address the molecular mechanism underlying the compromised suppressive effect of FcyRIIB-/MSCs, we compared the expression levels of Smad2, Smad3, and Cox-2, which are involved in inflammation response, between WT and FcyRIIB-/- MSCs by real-time quantitative PCR. Compared to FcүRIIB-/MSCs, WT MSCs expressed a 10-fold enhancement in Smad2, Smad3, and Cox-2 mRNA (Fig. 5A). The protein expression of Cox-2 was also downregulated in FcyRIIB-/- MSCs compared to WT MSCs (Fig. 5B). Moreover, the PGE2 production in the supernatants of cultured WT MSCs was significantly higher than that in cultured FcyRIIB-/- MSCs (P<0.001; Fig. 5C). These results suggest that the compromised suppressive function of FcyRIIB-deficient MSCs might be related to the reduced expression of the molecules mentioned above.
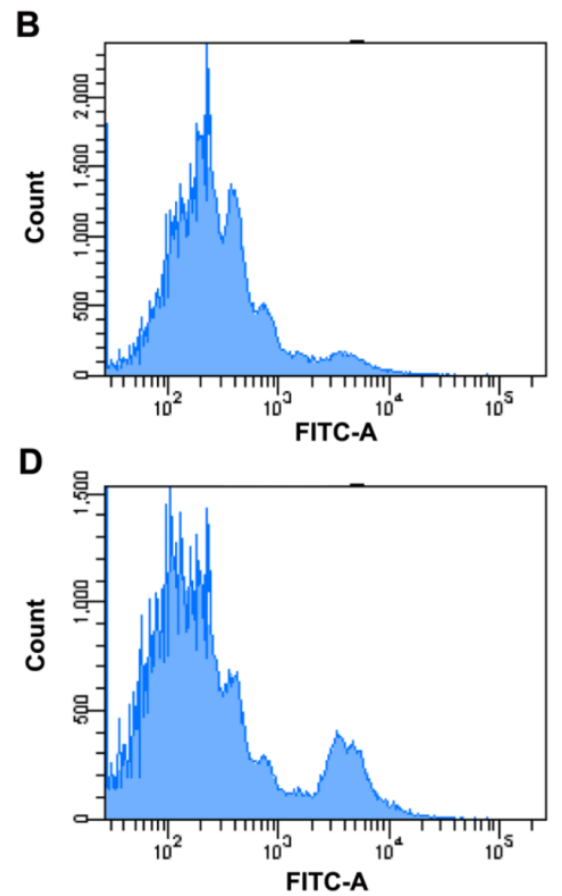

Figure 3. Effects of FcyRIIB on MSC-regulated antigen-specific T-cell response. CFSE-labeled OT-II T cells were purified and cultured with BMDCs in the presence (B, C, D) or absence (A) of $100 \mu M$ OVA peptide. (a) No OVA peptide, MFI=4498. (B) BMDCs were incubated with OVA peptide. MFI=587. (C) BMDCs were co-cultured with WT MSCs in the presence of OVA. MFI=1233. (D) BMDCs were co-cultured with FcyRIIB-/- MSCs in the presence of OVA. MFI=921. Cells were first gated on CD4+ population and then the CFSE level was analyzed using flow cytometry. Data were acquired by LSRII and analyzed with Flowjo software. Representative data of three individual experiments were presented. 


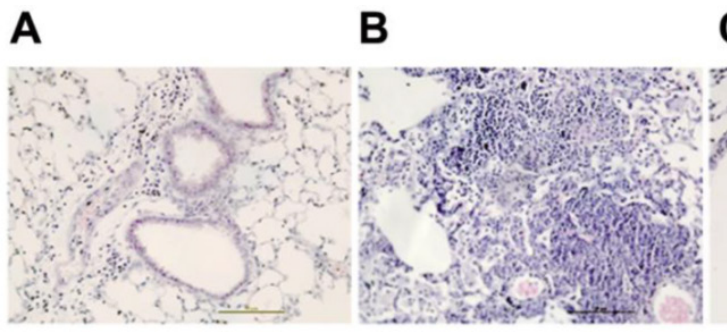

C D
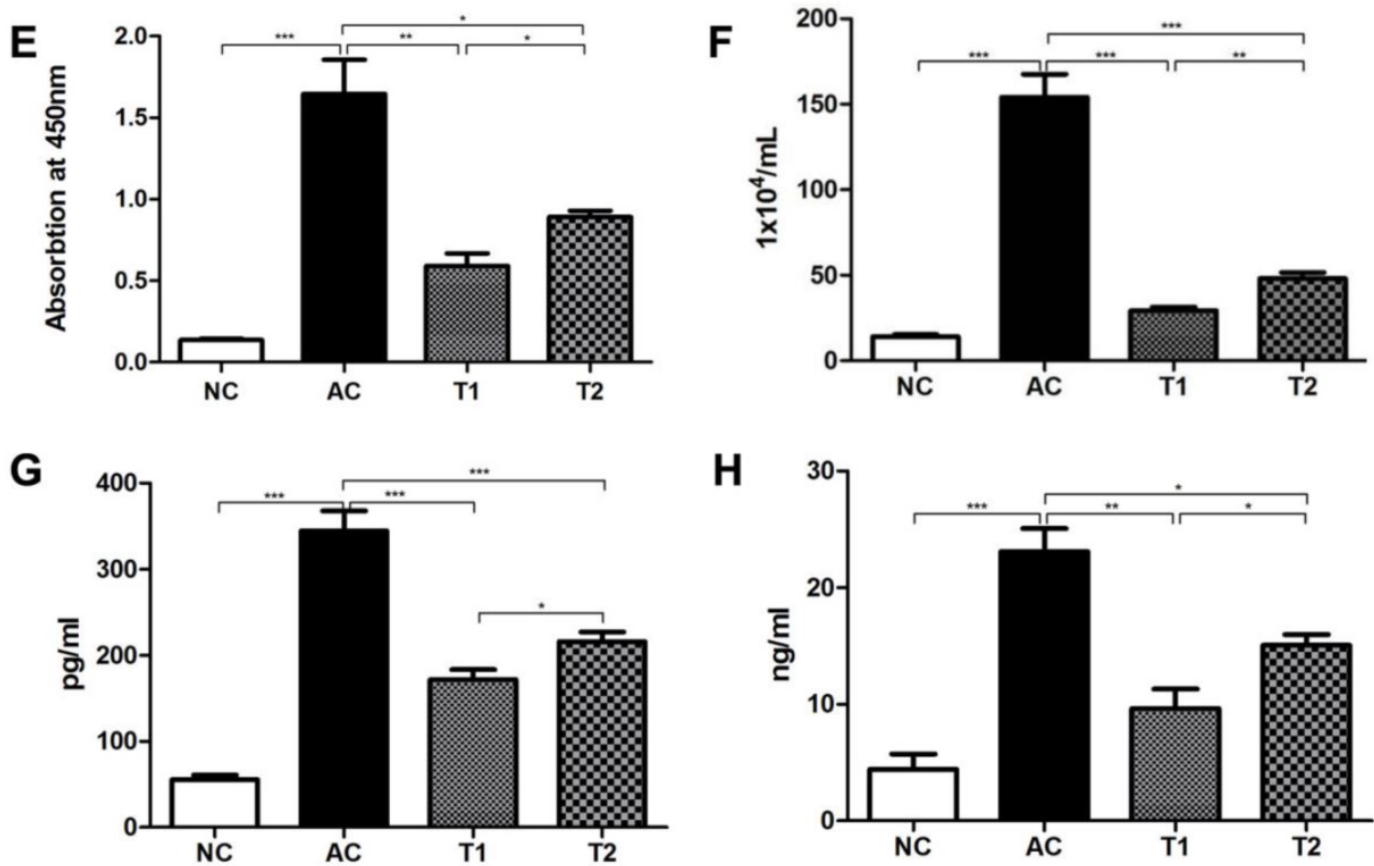

Figure 4. FcyRIIB-/-MSCs are less effective at controlling allergic asthma. Representative of three different animals are presented here. (A-D) Hematoxylin and eosin staining was used for histological examination of lung tissues. (A) Control mice; (B) asthma model mice; (C) asthma model mice that received WT MSC therapy; (D) and asthma model mice that received FcyRIIB-/- MSC therapy. (E) ELISA analysis of serum OVA-specific IgE production. (F) Total number of cells in BALF. Levels of IL-4 (G) and IL-13 (H) in BALF. NC, naive control; AC, asthma control; T1, asthma mice receiving WT MSC; T2: asthma mice receiving FcyRIIB-/- MSC. *P<0.05; $* * \mathrm{P}<0.001 ; * * * \mathrm{P}<0.0001 ; \mathrm{NS}, \mathrm{P}>0.05$.
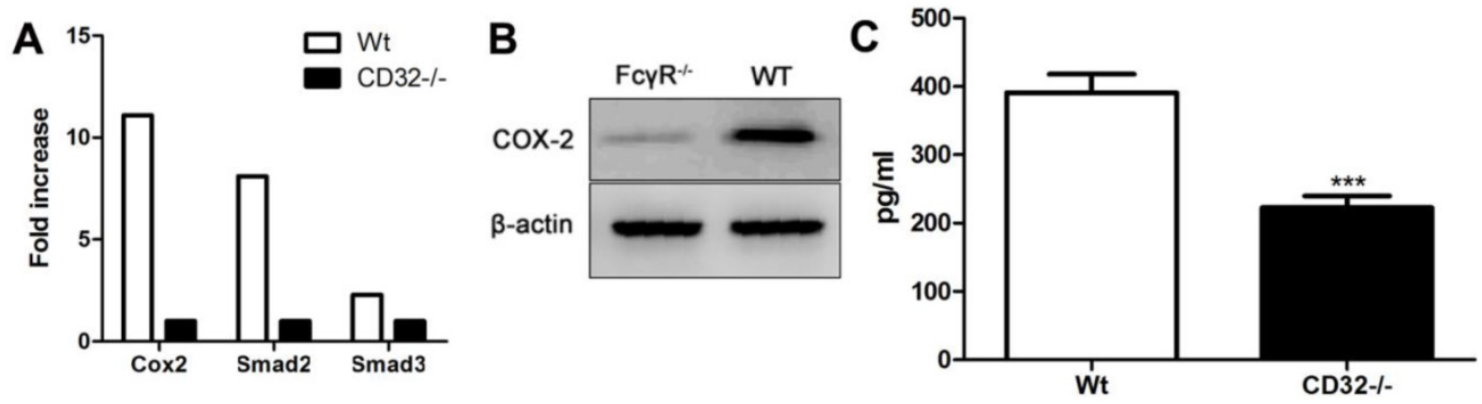

Figure 5. Reduced production of Smad2, Smad3, Cox-2, and PGE2 in FcyRIIB-/-MSCs. (A) Cox2, Smad2, and Smad3 mRNA expression in WT and FcyRIIB-/- MSCs was analyzed using real-time quantitative PCR. (B) Western blotting analysis of Cox-2 expression. Representative data of three independent experiments are presented. (C) EIA analysis of PGE2 production in the culture supernatant of WT and FcyRIIB-/- MSCs. $* * * P<0.0001$.

\section{Discussion}

MSCs are known to possess an array of immunosuppressive capabilities. For instance, MSCs suppress DC migration, maturation, and antigen presentation in vitro [14]. In addition, the immunosuppression properties of MSCs also include the MSC-mediated proliferation suppression of many immune cells, such as T lymphocytes, B lymphocytes, and natural killer cells [15]. Consistent with these findings, we also detected immunosuppression of DC maturation and function by MSCs derived from bone marrow. Moreover, intranasal administration of MSCs effectively modulated inflammation in an experimental model of asthma, which is in accordance with the results of a previous report [16]. 
FcyRIIB is known for its inhibitory role for B lymphocyte activation [17], and the absence of FcyRIIB facilitates the induction of autoimmune disease [18]. Baerenwaldt et al. demonstrated that FcyRIIB serves as a checkpoint of humoral tolerance in the human immune system, as impaired FcyRIIB function leads to the production of increased levels of serum immunoglobulins, the production of different autoantibody specificities, and an elevated generation of human plasmablasts and plasma cells in vivo [19]. In the present study, we found that MSCs derived from FcyRIIB-/- mice had restored function in mediating DC maturation. Our in vivo experiment further indicated that WT MSC therapy is more potent at decreasing inflammatory cytokine production than FcyRIIB-/- MSC therapy. These results suggest that FcyRIIB also plays a negative role in regulating MSC functions.

Smad2 and Smad3 are crucial intracellular mediators of airway inflammation that act through regulating transforming growth factor- $\beta$ (TGF- $\beta$ ) signaling [20]. Prostaglandins (PGs), such as PGE2, are the metabolic products of the Cox pathway, which play important roles in inflammation and asthma [21]. Our previous study revealed that immune complex induced massive PGE2 production in macrophages through FcyRII induction [22]. Blockage of PGE2 production by celecoxib restored LPS-induced endotoxin shock in FcyRIIB-/- mice, indicating FcyRIIB-mediated PGE2 production is essential in immune suppression [22]. Here, we detected the reduced Smad2, Smad3, Cox-2, and PGE2 production in FcyRIIB-/- MSCs, implying the inhibitory effects of FcyRIIB on MSCs might be related to the decreased expression of these molecules. However, the precise mechanism involved in this process still needs to be further clarified.

\section{Conclusions}

In summary, our study demonstrated for the first time that FcyRIIB might play an essential role in regulating the inhibitory effects of MSCs derived from bone marrow. These findings may provide valuable insights into developing novel strategies to improve the suppressive functions of MSCs in cell-based clinical therapy.

\section{Acknowledgments}

This study was supported by the National Nature Science Foundation of China (No. 81270073 and No. 81273319).

\section{Author contribution}

TYZ and RHC drafted the manuscript. ZL, JT and XXZ carried out the experiments. LRT and KDZ participated in the design of the study and performed the statistical analysis. YZY, CWD and CB conceived of the study, and participated in its design and coordination and helped to draft the manuscript. All authors read and approved the final manuscript.

\section{Conflicts of interest}

We declare that we have no conflicts of interest.

\section{References}

1 Beyer Nardi N, da Silva Meirelles L. Mesenchymal stem cells: isolation, in vitro expansion and characterization. Handb Exp Pharmacol. 2006: 249-282.

2 Ryan JM, Barry FP, Murphy JM, et al. Mesenchymal stem cells avoid allogeneic rejection. J Inflamm. (Lond) 2005; 2: 8

3 Barberini DJ, Freitas NP, Magnoni MS, et al. Equine mesenchymal stem cells from bone marrow, adipose tissue and umbilical cord: immunophenotypic characterization and differentiation potential. Stem Cell Res Ther. 2014; 5: 25.

4 Uccelli A, Moretta L, Pistoia V. Mesenchymal stem cells in health and disease. Nat Rev Immunol. 2008; 8: 726-736.

5 Knight DA, Rossi FM, Hackett TL. Mesenchymal stem cells for repair of the airway epithelium in asthma. Expert Rev Respir Med. 2010; 4: 747-758.

6 Kapoor S, Patel SA, Kartan S, et al. Tolerance-like mediated suppression by mesenchymal stem cells in patients with dust mite allergy-induced asthma. J Allergy Clin Immunol. 2012; 129: 1094-1101.

7 Nemeth K, Keane-Myers A, Brown JM, Metcalfe DD, et al. Bone marrow stromal cells use TGF-beta to suppress allergic responses in a mouse model of ragweed-induced asthma. Proc Natl Acad Sci U S A. 2010; 107: 5652-5657.

8 Swanson JA, Hoppe AD. The coordination of signaling during FC receptor-mediated phagocytosis. J Leukoc Biol. 2004; 76: 1093-1103.

9 Selvaraj P, Fifadara N, Nagarajan S, et al. Functional regulation of human neutrophil Fc gamma receptors. Immunol Res. 2004; 29: 219-230.

10 Trinchieri G, Valiante N. Receptors for the Fc fragment of IgG on natural killer cells. Nat Immun. 1993; 12: 218-234.

11 Joshi T, Butchar JP, Tridandapani S. Fcgamma receptor signaling in phagocytes. Int J Hematol. 2006; 84: 210-216.

12 El Haddad N, Heathcote D, Moore R, et al. Mesenchymal stem cells express serine protease inhibitor to evade the host immune response. Blood. 2011; 117: 1176-1183.

13 Idzko M, Hammad H, van Nimwegen M, et al. Local application of FTY720 to the lung abrogates experimental asthma by altering dendritic cell function. J Clin Invest. 2006; 116: 2935-2944.

14 English K, Barry FP, Mahon BP. Murine mesenchymal stem cells suppress dendritic cell migration, maturation and antigen presentation. Immunol Lett. 2008; 115: 50-58.

15 Shi Y, Hu G, Su J, et al. Mesenchymal stem cells: a new strategy for immunosuppression and tissue repair. Cell Res. 2010; 20: 510-518.

16 Abreu SC, Antunes MA, de Castro JC, et al. Bone marrow-derived mononuclear cells vs. mesenchymal stromal cells in experimental allergic asthma. Respir Physiol Neurobiol. 2013; 187: 190-198.

17 Nimmerjahn F, Ravetch JV. Fcgamma receptors as regulators of immune responses. Nat Rev Immunol. 2008; 8: 34-47.

18 Clynes R, Calvani N, Croker BP, et al. Modulation of the immune response in pristane-induced lupus by expression of activation and inhibitory Fc receptors. Clin Exp Immunol. 2005; 141: 230-237.

19 Baerenwaldt A, Lux A, Danzer H, et al. Fcgamma receptor IIB (FcgammaRIIB) maintains humoral tolerance in the human immune system in vivo. Proc Natl Acad Sci U S A. 2011; 108: 18772-18777.

20 Groneberg DA, Witt H, Adcock IM, et al. Smads as intracellular mediators of airway inflammation. Exp Lung Res. 2004; 30: 223-250.

21 Claar D, Hartert TV, Peebles RS, Jr. The role of prostaglandins in allergic lung inflammation and asthma. Expert Rev Respir Med. 2015; 9: 55-72.

22 Zhang Y, Liu S, Liu J, et al. Immune complex/Ig negatively regulate TLR4-triggered inflammatory response in macrophages through Fc gamma RIIb-dependent PGE2 production. J Immunol. 2009; 182: 554-562. 